Saad S Gasgoos

BDS, MSc (Lect)

Ra'ed J Sa'id

BDS, MSc (Assist Lect)

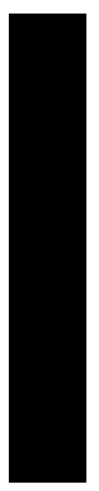

\section{The Effect of Thermocycling on Shear Bond Strength of Two Types of Self- Etch Primers}

\author{
Dept of Pedod, orthod, and Prev Dentistry \\ College of Dentistry, University of Mosul
}

\begin{abstract}
Aims: To determine the shear bond strength of two types of self-etch primer (Transbond plus 3M Unitek, USA made and Clearfil, Japan made) when used to bond metal orthodontic brackets to enamel surface after thermocycling test and water storage for two months and to check the failure site after debonding using adhesive remnant index. Materials and methods: sixty extracted upper first premolars for orthodontic reason were used in this study; 30 teeth were bonded with light curing Transbond plus $3 \mathrm{M}$ Unitek and the other 30 teeth were bonded with light curing Clearfil self-etch primers. For both groups, Dentaurum stainless steel orthodontic brackets were bonded to enamel surface with Transbond XT light curing composite. Then 10 samples from each groups were tested for shear bond strength after 24 hours, the other 10 samples from each groups were tested after 500 manual thermocycles between $5^{\circ} \mathrm{C} \& 55^{\circ} \mathrm{C}$, the third 10 samples of each groups were tested after 500 thermocycles and 2 months water storage at room temperature. The adhesive remnant index was tested under 10X magnification lens. Results: Both materials demonstrated a very good shear bond strength before thermocycling (14.5825 MPa for 3M Unitek \& 14.3966 MPa for Clearfil groups). After 500 thermocycles, there were no significant changes in shear bond strength for both materials (15.0567 MPa for 3M Unitek \& 13.997 MPa for Clearfil groups) and this is clinically acceptable. After 500 thermocycles and two months water storage the shear bond strength of the $3 \mathrm{M} /$ Unitek reduced progressively below the acceptable clinical value (3.469 MPa), whereas the shear bond strength of Clearfil group still above the acceptable level (10.607 MPa). The tendency of bond failure at the enamel-adhesive interface was increased after thermocycling and water storage. Conclusions: this study was done in vitro and further in vivo investigations are needed to evaluate these 2 materials.
\end{abstract}

Key words: Thermocycling, Water storage, Self etch primers, Shear bond strength.

Gasgoos SS, Sa'id RJ. The Effect of Thermocycling on shear Bond Strength of Two Types of SelfEtch Primers. Al-Rafidain Dent J. 2009; 9(2): 246-253.

Received: 6/5/2008

Sent to Referees: 6/5/2008

Accepted for Publication: 17/8/2008

\section{INTRODUCTION}

Thermocycling simulates the temperatur dynamics in the oral environment, with direct bonding; thermocycling reduces the bond strength of orthodontic adhesives ${ }^{(1)}$.

Orthodontic adhesives are routinely exposed to temperature variations in oral cavity. Air temperature, humidity, and air velocity when breathing can also alter resting mouth temperature ${ }^{(2)}$. Although these variations are erratic and hard to anticipate when testing, it is important to determine whether they introduce stresses in the adhesive that might influence its bond strength. Therefore, Bishara et al., ${ }^{(3)}$ have suggested that thermal cycling should be part of the testing protocol of new adhe- sives.

In vivo, Transbond specimens debonded after 4 weeks had significantly lower bond strength $(9.78 \mathrm{Mpa})$ than did the controls $(14.34 \mathrm{Mpa})^{(4)}$. A significant decrease in bond strength after thermocycling have been observed using brackets bonded with three different glass ionomer cements and an autopolymerizing composite resin, with the resin showing the greatest decrease ${ }^{(5)}$. Other study found an $11.1 \%$ and $26.5 \%$ reduction in bond strength after 200 and 20,000 thermocycles, respectively, for a resin-modified glass ionomer and a $5.7 \%$ and $17.9 \%$ reduction for a composite $\operatorname{resin}^{(6)}$. Whereas other study found an $80 \%$ decrease in 
bond strength of a cyanoacrylate orthodontic adhesive after thermocycling ${ }^{(3)}$.

Although phosphoric acid etching still seems to be the most frequently used method for enamel preparation ${ }^{(7,8)}$, enamel damage from debonding still is a major clinical problem. In contrast, self-etching primers show much less etching ability because of their relatively higher $\mathrm{PH}$ as compared with phosphoric acid etching $(9,10)$, thus minimizing the potential for iatrogenic damage to enamel.

Researchers have tested alternative enamel conditioners, such as maleic acid primers, to determine if they can attain clinically useful bond strength while decreasing the depth of enamel dissolution and decreasing the number of steps during the bonding procedure ${ }^{(11)}$. Conventional bonding systems used 3 steps to prepare enamel surfaces: an enamel conditioner, a primer solution, and an adhesive resin ${ }^{(12)}$, so that the time saved by the use of a selfetching primer is more than that spent in the preparation of the adhesive before bonding ${ }^{(13)}$.

A study used computerized three dimentional scanner to measure enamel loss caused by orthodontic bonding and debonding after phosphoric acid etching and reported an average loss of enamel of $7.4 \mu \mathrm{m}^{(14)}$. Using field emission scanning electron microscopy observed more dissolution of the enamel surface resulting from phosphoric acid etching $(5-50 \mu \mathrm{m})$ than from self-etching primer treatment ${ }^{(15,16)}$.
The shear bond strength of orthodontic brackets to enamel have been compared using $37 \%$ phosphoric acid, $10 \%$ maleic acid, or an acidic primer solution containing the acidic phenyl-p and a hydrophilic primer consisting of hydroxy methyl methacrylate and dimethacrylate. That study demonstrated that acidic primer systems used to bond orthodontic brackets to tooth enamel could provide acceptable shear strength $^{(11)}$.

The aims of this study are to determine the shear bond strength of two types of self-etch primers (Transbond Plus 3M Unitek, USA made \& Clearfil, Japan made) when used to bond metal orthodontic brackets to enamel after thermocycling test and water storage for two months, and to measure the failure site after debonding in the three conditions using adhesive remnant index (ARI).

\section{MATERIALS AND METHODS}

In this study two types of self-etch primers are used (Clearfil SE bond, made in Japan and Transbond ${ }^{\mathrm{TM}}$ plus $3 \mathrm{M} /$ Unitek, made in USA). The compositions of these two materials are presented in Table (1).

To exclude the possible differences in bond strength caused by the orthodontic adhesive, all brackets were bonded with the same material (Light-cure highly filled orthodontic adhesive Transbond XT 3M/ Unitek, Monrovia, Calif, made in USA) ${ }^{(17)}$.

Table (1): Composition of self-etching adhesive systems used in present study.

\begin{tabular}{cc}
\hline Test Material & Composition \\
\hline $\begin{array}{c}\text { Transbond Plus } \\
\text { 3M Unitek }\end{array}$ & $\begin{array}{c}\text { Bonding agent A:MAC-10, photoinitiator, methacryloyloxyalkyl acid } \\
\text { phosphate, BisGMA, TEGDMA. }\end{array}$ \\
& $\begin{array}{c}\text { Bonding agent B:methyl methacrylate, HEMA, water, F-deliverable } \\
\text { micro filler, photoinitiator. }\end{array}$
\end{tabular}

Primer:MDP, HEMA, hydrophilic dimethacrylate, dicamphoroquinoneN, N-diethanol-p-toluidine, water.

Clearfil SE Bond Adhesive:10-MDP, Bis-GMA, HEMA, silanated colloidal silica, hydrophilic dimethacrylate, di-camphoroquinoneN, N-diethanol-ptoluidine.

MAC: methacrylate; BisGMA: isphenol-glycidil methacrylate; TEGDMA: triethyleneglycol dimethacrylate; HEMA: 2-hydroxyethyl methacrylate; MDP: methacryloxymethacrylate. 
Sixty freshly extracted human maxillary first premolar for orthodontic reason were collected and stored in a solution of $0.1 \%$ thymol. The criteria for tooth selection included intact buccal enamel, not subjected to any pretreatment chemical agents, no cracks, and no caries ${ }^{(18)}$. The teeth were poured in metal rings using cold-cure acrylic resin and numbered randomly, then the teeth were polished with non-fluoridated pumice using prophylactic rubber cup for 10 seconds ${ }^{(13,17,19)}$.

A stainless steel metal brackets (Dentaurum type) of maxillary first premolar with an average base surface area of 10.5 $\mathrm{mm}^{2}$ were used in this study. Then the teeth were randomly divided in to two groups, each group consist of 30 teeth, and bonded as follows (Table 2):

The first group was bonded using Clearfil SE bond; The primer was applied for 20 seconds then dried with mild air flow (without water), then the bond was applied and air flow gently and cured with Halogen bulb light-cure device (Dentsply type) for 10 seconds. The second group was bonded using Transbond $^{\mathrm{TM}}$ plus $3 \mathrm{M} /$ Unitek etching primer; The two components were squeezed together and mixed well before application on the enamel surface for 3-5 seconds and then gently evaporated with air for 5 seconds.
For both groups the orthodontic brackets bonded to tooth surface using Transbond XT composite under finger pressure, the access composite was removed with sharp scaler and light cured for 20 seconds (10 seconds on each side $)^{(18)}$. Group of 5 teeth was bonded at a time to simulate the bonding of each quadrant in the oral cavity.

The specimens were stored in water at $37 \pm 2^{\circ} \mathrm{C}$ for 24 hours to discriminate between those materials that can and those that cannot withstand a wet environment. After 24 hours, 10 samples of Clearfil SE group \& 10 samples of Transbond ${ }^{\mathrm{TM}}$ plus $3 \mathrm{M} /$ Unitek were debonded at room temperature, whereas the others were thermocycled between $5^{\circ} \mathrm{C}$ and $55^{\circ} \mathrm{C}$ for 500 complete cycles. The thermocycling was done manually following the recommendation of the international Organization for Standardization ${ }^{(20)}$, the exposure to each bath was 20 seconds, and the transfer time between the two baths was 5-10 seconds. Debonding was also performed at room temperature for 10 samples of Clearfil SE group \& 10 samples of Transbond ${ }^{\mathrm{TM}}$ plus $3 \mathrm{M} /$ Unitek, the remaining 10 samples of each group were stored in distilled water at room temperature for 2 months before debonding.

Table (2): Sample distribution.

\begin{tabular}{ccc}
\hline & $\begin{array}{c}\text { Transbond } \\
\text { Unitek } \\
\text { (No. of Specimens) }\end{array}$ & $\begin{array}{c}\text { Clearfil SE Bond (No. } \\
\text { of Specimens) }\end{array}$ \\
\hline $\begin{array}{c}\text { Debonding After 24 Hours } \\
\text { Debonding After 500 Thermocy- } \\
\text { cles }\end{array}$ & 10 & 10 \\
$\begin{array}{c}\text { Debonding After 500 Thermocy- } \\
\text { cles and 2 Months Water Storage }\end{array}$ & 10 & 10 \\
Total Sample & 30 & 10 \\
\hline
\end{tabular}

The debonding was done on the unconfined shear testing machine. A knifeedge shearing blade was secured on the cross head with the direction of force parallel to facial surface and the bracket interface. The shearing blade struck flush against the edge of the base without touching the enamel. Bond strength was meas- ured at a crosshead speed of $1 \mathrm{~mm} / \mathrm{min}$ ute ${ }^{(17,21)}$. The force required to dislodge the bracket was recorded in Newton and converted to Megapascals with the following equation:

Shear force $(\mathrm{MPa})=$ debonding force $(\mathrm{N}) /$ surface area of bracket base $\left(\mathrm{mm}^{2}\right)$, so that $1 \mathrm{MPa}=1 \mathrm{~N} / \mathrm{mm}^{2}$. After debonding, the 
teeth and brackets were examined with 10X lens magnifications. The debonding condition of each specimen was scored using the adhesive remnant index $(\text { ARI })^{(22)}$. The ARI scores ranged from 0 3 , ie, score $0=$ no adhesive remained on the enamel; $1=$ less than half of the adhesive remained on the tooth surface; $2=$ more than half of the adhesive remained on the tooth surface; $3=$ all the adhesive remained on the tooth surface with a distinct impression of the bracket base.

Student T-test was performed between Transbond ${ }^{\mathrm{TM}}$ plus 3M/Unitek and Clearfil groups before thermocycling, after thermocycling, and after thermocycling and water storage to determine the difference in shear bond strength of the 2 materials. It is considered significant when $p \leq 0.05$. One-way analysis of variance (ANOVA) and Duncan's multiple range analysis tests were used for both materials before thermocycling, after thermocycling, and after thermocycling and water storage to show the difference between the 2 materials in the three phases. It is considered significant when $p \leq 0.05$.

To assess the difference in the failure site of bracket between the 2 materials in the three phases, the two sample Kolmogorov-Smirnov test and Kruskal-Wallis test were used in this study. It is considered significant when $p \leq 0.05$.

RESULTS
Shear Bond Strength:
The descriptive statistics for the shear
bond strength of both $3 \mathrm{M} /$ Unitek and
clearfil groups in the three conditions (be-
fore thermocycling, after thermocycling,
and after both thermocycling and storage)
are presented in Table (3).

Table (3): Descriptive statistics of shear bond strength for 3M Unitek and Clearfil before thermocycling, after thermocycling and after both thermocycling and 2 months water storage.

\begin{tabular}{cccccc}
\hline & Material & No. & Mean* & \pm SD & SE Mean \\
\hline \multirow{2}{*}{ Before Thermocycling } & 3M/Unitek & 10 & 14.58250 & 4.337538 & 1.371650 \\
& Clearfil & 10 & 14.39660 & 3.043000 & 0.962281 \\
\hline \multirow{2}{*}{ After Thermocycling } & 3M/Unitek & 10 & 15.05670 & 2.521552 & 0.797385 \\
& Clearfil & 10 & 13.99700 & 2.060792 & 0.651680 \\
\hline After Thermocycling & 3M/Unitek & 10 & 3.46900 & 1.178346 & 0.372626 \\
and Water Storage & Clearfil & 10 & 10.60700 & 4.617207 & 1.460089 \\
\hline
\end{tabular}

* The mean in $\mathrm{MPa}\left(\mathrm{N} / \mathrm{mm}^{2}\right)$; No: number; SD: standerd deviation; SE: standerd error.

In Table (4) the comparative statistical $t$-test between $3 \mathrm{M} /$ Unitek samples and Clearfil samples indicated that there were a non significant differences in shear bond strength at level of $95 \%$ confidence interval of the difference before thermocycling groups and after 500 thermocycles, whereas after 500 thermocycles and 2 months water storage this test shows a high significant difference between 3M/Unitek and Clearfil groups because of a great reduction in shear bond strength for $3 \mathrm{M} /$ Unitek group. The $3 \mathrm{M} /$ Unitek group when tested in the three phases (before thermocycling, after thermocycling, and after both thermocycling \& storage) using one way analysis of variance and Duncan's multiple range analysis test (Tables 5, 6) shows that there were non significant difference in shear bond strength before thermocycling and after 500 thermocycle, but the groups that tested after 500 thermocycle and 2 months water storage were significantly have lower shear bond strength. The same results were shown in Tables $(7,8)$ for the Clearfil groups. 
Table (4): Comparison of shear bond strength of $3 \mathrm{M} /$ Unitek and Clearfil before thermocycling, after thermocycling and after both thermocycling and 2 months water storage.

\begin{tabular}{cccccc}
\hline & \multicolumn{2}{c}{ T-test for Equality of Means } & \multicolumn{2}{c}{$\mathbf{9 5 \%}$ Confidence Interval } \\
\cline { 2 - 6 } & T-value & df & $\boldsymbol{p}$-value & Lower & Upper \\
\hline Before Thermocycling & 0.111 & 18 & 0.913 & -3.334263 & 3.706063 \\
After Thermocycling & 1.029 & 18 & 0.317 & -1.103851 & 3.223251 \\
$\begin{array}{c}\text { After Thermocycling and } \\
\text { Water Storage }\end{array}$ & -4.737 & 18 & 0.000 & -10.303853 & -3.972147 \\
\hline
\end{tabular}

df: degree of freedom.

Table (5): One way analysis of variance of 3M/Unitek self-etch primer.

\begin{tabular}{lccccc} 
& Sum of Squares & df & Mean Square & F-value & p-value \\
\hline Factor & 860.032 & 2 & 430.016 & \multirow{2}{*}{48.569} & \multirow{2}{*}{0.000} \\
Error & 239.049 & 27 & 8.854 & & \\
\hline Total & 1099.080 & 29 & & & \\
\hline df: degree of freedom. & & & &
\end{tabular}

df: degree of freedom.

Table (6): Duncan's Multiple Range Test of 3M/Unitek self-etch primer.

\begin{tabular}{cccc}
\hline Groups & No. & Mean* \pm SD & $\begin{array}{c}\text { Duncan's Group- } \\
\text { ing** }\end{array}$ \\
\hline $\begin{array}{c}\text { After Thermocycling and } \\
\text { Water Storage }\end{array}$ & 10 & $3.46900 \pm 1.178346$ & $\mathrm{~A}$ \\
$\begin{array}{c}\text { Before Thermocycling } \\
\text { After Thermocycling }\end{array}$ & 10 & $14.58250 \pm 4.337538$ & $\mathrm{~B}$ \\
\hline
\end{tabular}

* The mean in $\mathrm{MPa}\left(\mathrm{N} / \mathrm{mm}^{2}\right)$; No: number; SD: standerd deviation ; **Means with same letter were statistically not significant $(p>0.05)$.

Table (7): One way analysis of variance of Clearfil self-etch primer.

\begin{tabular}{cccccc}
\hline & Sum of Squares & df & Mean Square & F-value & $\boldsymbol{p}$-value \\
\hline Factor & 86.709 & 2 & 43.355 & \multirow{2}{*}{3.735} & 0.037 \\
Error & 313.428 & 27 & 11.608 & & \\
\hline Total & 400.137 & 29 & & & \\
\hline
\end{tabular}

df: degree of freedom.

Table (8): Duncan's Multiple Range Test of Clearfil self-etch primer.

\begin{tabular}{cccc}
\hline Groups & No. & Mean* \pm SD & $\begin{array}{c}\text { Duncan's Group- } \\
\text { ing*** }\end{array}$ \\
\hline $\begin{array}{c}\text { After Thermocycling and } \\
\text { Water Storage }\end{array}$ & 10 & $10.60700 \pm 4.617207$ & $\mathrm{~A}$ \\
$\begin{array}{c}\text { After Thermocycling } \\
\text { Before Thermocycling }\end{array}$ & 10 & $13.99700 \pm 2.060792$ & $\mathrm{~B}$ \\
\end{tabular}

* The mean in MPa (N/mm²); No: number; SD: standerd deviation **Means with same letter were statistically not significant $(p>0.05)$. 
Adhesive Remnant Index and Failure Site:

The adhesive remnant index between orthodontic brackets and enamel surface were presented in Table (9). The twosample Colmogorove-Smirnov test was used to show the difference in failure site for the 2 materials before thermocycling, after thermocycling, and after both thermocycling \& water storage phases which indicated that there were non significant difference between them (Table 10).

The adhesive remnant index were compared between 3M/Unitek and Clearfil groups using Kruskal-wallis test (Table 11) showed that the adhesive remnant index in $3 \mathrm{M} /$ Unitek samples after thermocycling and water storage was significantly differ from the remaining samples (In all 10 samples the failure occure at the enamel-adhesive interface).

Table (9): Adhesive Remnant Index frequency distribution.

\begin{tabular}{|c|c|c|c|c|}
\hline Group & 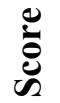 & $\begin{array}{l}\text { Before Thermo- } \\
\text { cycling }\end{array}$ & $\begin{array}{l}\text { After Thermo- } \\
\text { cycling }\end{array}$ & $\begin{array}{c}\text { After Thermocycling \& } \\
\text { Water Storage }\end{array}$ \\
\hline \multirow{4}{*}{ 3M/Unitek } & 0 & 5 & 8 & 10 \\
\hline & 1 & 3 & 1 & 0 \\
\hline & 2 & 2 & 1 & 0 \\
\hline & 3 & 0 & 0 & 0 \\
\hline \multirow{4}{*}{ Clearfil* } & 0 & 6 & 7 & 9 \\
\hline & 1 & 4 & 2 & 1 \\
\hline & 2 & 0 & 0 & 0 \\
\hline & 3 & 0 & 0 & 0 \\
\hline
\end{tabular}

*Fracture enamel in one sample of Clearfil group after thermocycling have been excluded from the study.

Table (10): Statistical analysis between 3M/Unitek and Clearfil materials before thermocycling, after thermocycling and after both thermocycling and 2 months

\begin{tabular}{cccc}
\multicolumn{4}{c}{ water storage (Kolmogorov-Smirnov Test). } \\
\hline Group & $\mathbf{Z}$ value & $\mathbf{D}$ (absolute) & $\boldsymbol{p}$-value \\
\hline $\begin{array}{c}\text { Before thermocycling } \\
\text { After thermocycling }\end{array}$ & 0.44 & 0.200 & $0.988^{*}$ \\
$\begin{array}{c}\text { After thermocycling and } \\
\text { storage }\end{array}$ & 0.218 & 0.100 & $1.000^{*}$ \\
\hline
\end{tabular}

* not significant $(p>0.05)$.

Table (11): Statistical analysis among before thermocycling, after thermocycling and after both thermocycling and 2 months water storage for the two materials (KruskalWallis Test).

\begin{tabular}{cccc}
\hline Group & $\boldsymbol{\chi}^{\mathbf{2}}$ & df & $\boldsymbol{p}$-value \\
\hline 3M/Unitek & 6.623 & 2 & $0.036(\mathrm{~S})$ \\
Clearil & 2.398 & 2 & 0.301 (NS) \\
\hline
\end{tabular}

df: degree of freedom; S: significant difference; NS: no signifinat difference.

DISCUSSION

Bond strength should not only be high enough to resist the forces during the course of orthodontic treatment but also low enough to allow the removal of the bracket without any complications at the end of orthodontic treatment.
In this study the shear bond strength of $3 \mathrm{M} /$ Unitek and Clearfil before thermocycling and after 500 thermocycle was not significantly changed. This result is supported by Hasegawa et al., ${ }^{(23)}$ who reported that subjecting specimens to 500 cycles might not affect bond strength, de- 
pending on the adhesive system used. Other study shows in its results a reduction in shear bond strength of self-etch primer but after 10.000 thermocycles ${ }^{(24)}$.

The other factor concern in the biodegradation of the adhesive and composite as a result of immersion in water or exposure to oral fluids leading to decrease in bond strength values over time. So the reduction in shear bond strength after thermocycling and water storage for 2 months was significant in this study. These results are also supported by Murray and Hobson ${ }^{(25)}$ who demonstrated a significant loss of bond strength in brackets bonded with Transbond after they were immersed in water in vitro or exposed to oral environment for as long as 12 weeks.

The reduction in shear bond strength for both Clearfil and 3M/unitek groups after thermocycling and water storage may possibly be explained by the absorption of water and the alternating stressing of the system resulting from the large mismatch of the thermal expansion coefficient of different surfaces ${ }^{(26)}$; of the adhesives $\left(\alpha=20-55 \mathrm{ppm} /{ }^{\circ} \mathrm{C}\right)$ with those of the stainless steel bracket $\left(\alpha=16 \mathrm{ppm} /{ }^{\circ} \mathrm{C}\right)$ and ena$\operatorname{mel}\left(\alpha=16 \mathrm{ppm} /{ }^{\circ} \mathrm{C}\right)$.

It is logical to assume that water storage was another major contributing to the low bond strength achieved with the selfetch primer and adhesive system in our study. Water diffusion into the bonding interface causes the resinous components to swell and become plasticized ${ }^{(27)}$. During the thermal cycling test, hot water might accelerate the hydrolysis of the resin and extract poorly polymerized resin oligomers $^{(28)}$.

The adhesive remnant index scores indicated that brackets bonded with either material showed a similar range of bond failure mode in each phase. There is an increase in the risk of adhesive failure occur at enamel-adhesive after thermocycling and water storage, this may be advantageous to leave enamel surface clean after debonding and not need bur cleaning ${ }^{(19,29)}$, however this result may be of controversy. As an example, bracket failure at the bracket/adhesive interface is advantageous because it leaves the enamel surface relatively intact. However, considerable chair time is needed to remove the residual adhesive, with the added possibility for damaging the enamel surface during the cleaning process. Conversely,when brackets fail at the enamel/adhesive interface, less residual adhesive remain, but the enamel surface can be damaged when failure occurs in this mode.

\section{CONCLUSIONS}

The use of single step self-etch systems, in terms of simplifying clinical procedures, might have benefits even after exposure to a number of thermal cycles simulating conditions in oral environment. However, it should be born in mind that these results were obtained under in vitro conditions.

\section{REFERENCES}

1.Daub J, Berzins DW, Linn BJ, Bradley TG. Bond strength of direct and indirect bonded brackets after thermocycling. Angle Orthod. 2006; 76(2): 295-300.

2.Gale MS, Darvell BW. Thermal cycling procedures for laboratory testing of dental restorations. J Dent. 1999; 27(1): 89-99.

3.Bishara SE, Ajlouni R, Laffoon JF. Effect of thermocycling on the shear bond strength of a cyanoacrylate orthodontic adhesive. Am J Orthod Dentofacial Orthop. 2003; 123(1): 21-24.

4.Murray SD, Hobson RS. Comparison of in vivo shear bond strength. Am J Orthod Dentofacial Orthop. 2003; 123(1): 2-9.

5.Klockowski R, Davis EL, Joynt RB, Wieczkowski G Jr, MacDonald A. Bond strength and durability of glass ionomer cements used as bonding agents in the placement of orthodontic brackets. Am J Orthod Dentofacial Orthop. 1989; 96: 6064.

6.Arici S, Arici N. Effects of thermocycling on the bond strength of a resin-modified glass ionomer cement: an in vitro comparative study. Angle Orthod. 2003; 73(6): 692-696.

7.Canay S, Kocadereli I, Akça E. The effect of enamel air abrasion on the relation of bonded metallic brackets. Am J Orthod Dentofacial Orthop. 2000; 117: 15-9.

8.Kocadereli I, Canay S, Akça K. Tensile bond strength of ceramic orthodontic brackets bonded to porcelain surface. Am J 
Orthod Dentofacial Orthop. 2001; 119: 17-20.

9.Cehreli ZC, Altay N. Effects of a nonrince conditioner and $17 \%$ ethylenediaminetetraacetic acid on the etch pattern of intact human permanent enamel. Angle Orthod. 2000; 70(1): 22-27.

10.Cehreli ZC, Altay N. Etching effect of $17 \%$ EDTA and a non-rinse conditioner (NRC) on primary enamel and dentin. Am J Dent. 2000; 13(3): 64-68.

11. Bishara SE, Gordan VV, VonWald L, Olson ME. Effect of an acid primer on shear bond strength of orthodontic brackets. Am J Orthod Dentofacial Orthop. 1998; 114(3): 243-247.

12.Miller RA. Laboratory and clinical evaluation of a self-etching primer. J Clin Orthod. 2001; 35: 171-178.

13.Saito K, Sirirungrojying S, Meguro D, Hayakawa T, Kasai K. Bonding durability of using self-etching primer with 4META/MMA-TBB resin cement to bond orthodontic brackets. Angle Orthod. 2005; 75(2): 256-261.

14.Van Waes H, Matter T, Krejci I. Threedimensional measurement of enamel loss caused by bonding and debonding of orthodontic brackets. Am J Orthod Dentofacial Orthop. 1997; 112(3): 666-669.

15.Kawasaki M, Hayakawa T, Takizawa T, Sirirungrojying S, Saitoh K, Kasai K. Assessing the performance of a methyl methacrylate-based resin cement with selfetching primer for bonding orthodontic brackets. Angle Orthod. 2003; 73(6): 702709.

16.Milia E, Lallai MR. In vivo effect of a self-etching primer on dentin. Am J Dent. 1999; 12: 167-171.

17.Cehreli ZC, Kecik D, Kocadereli I. Effect of self-etching primer and adhesive formulations on the shear bond strength of orthodontic brackets. Am J Orthod Dentofacial Orthop. 2005; 127(5): 573-579.

18. Bishara SE, Oonsombat C, Soliman MA, Warren JJ, Laffoon JF, Ajlouni R. Comparison of bonding time and shear bond strength between a conventional and a new integrated bonding system. Angle Orthod. 2005; 75(2): 233-238.

19.Bishara SE, Ostby AW, Laffoon JF, War- ren J. Shear bond strength comparison of two adhesive systems following thermocycling. Angle Orthod. 2007; 77(2): $337-$ 341.

20.International Organization for Standardization. 1994. Dental Materials-Guidance on Testing on Adhesion to Tooth Structure. Geneva, Switzerland ISO TR 11405.

21.EndoT, Yoshino S, Shinkai K, Ozoe R, Shimada M, Katoh Y, Shimooka S. Shear bond strength differences of types of maxillary deciduous and permanent teeth used as anchor teeth. Angle Orthod.2007; 77(3): 537-541.

22.Artun J, Bergland S. Clinical trials with crystal growth conditioning as an alternative to acid pretreatment. Am J Orthod. 1984; 85(3): 333-340.

23.Hasegawa T, Retif DH, Russell CM, Denys FR. Shear bond strength and quantitative microleakage of a multipurpose dental adhesive system resin bonded to dentin. $J$ Prosthetic Dent. 1995; 73: 432-8.

24.EL Araby AM, Talic YF. The effect of thermocycling on the adhesion of selfetching adhesives on dental enamel and dentin. J Contemp Dent Prac. 2007; 8(2): $17-24$.

25.Murray SD, Hobson RS. Comparison of in vivo and in vitro shear bond strength. Am J Orthod Dentofacial Orthop. 2003; 123(1): 2-9.

26.Anusavice KJ. Phillip's Science of Dental Materials. $11^{\text {th }}$ ed. St Louis. Mo: Saunders. 2003; P: 55.

27.Söderholm KJ. Correlation of in vivo and in vitro performance of adhesive restorative materials: a report of the ASC MD156 task group on test methods for the adhesion of restorative materials. Dent Mater. 1991; 7: 74-83.

28. Hashimoto M, Ohno H, Sano H, Tay FR, Kaga M, Kudou Y, Oguchi H, Araki Y, Kubota M. Micromorphological changes in resin-dentin bonds after 1 year of water storage. J Biomed Mater Res. 2002; 63: 306-311.

29.Harari D, Gillis I and Redlich M. Shear bond strength of a new dental adhesive used to bond brackets to unetched enamel. Eur J Orthod. 2002; 24: 519-523. 